JELTL (Journal of English Language Teaching and Linguistics) e-ISSN: 2502-6062, p-ISSN: 2503-1848

2018, Vol. 3(3)

www.jeltl.org

\title{
Teaching English As Second Language through Drama for Effective Communication Skills: A Pragmatic Perspective
}

\author{
Joseph Agofure Idogho \\ Federal University Oye -Ekiti, Ekiti State, Nigeria \\ e-mail:agofurei@gmail.com
}

\begin{abstract}
Literatures have reveal that teaching English Language in a conventional classroom with all the available methodology hardly gives the students opportunity to use the language effectively or gain the competence and confidence of using the language in and outside the classroom and probably develop fluency in it: especially when English is a second language other than the learner's language like the Nigeria situation. This paper thus opines that with the use of drama as a tool or technique in teaching English Language as second language; learners would be equipped with the essential skills of communication and gain fluency in the language. This paper therefore explores the array of models through which language exploration through drama is related to Language Acquisition theories. The paper examines the theories of Language acquisition to establish the relevance of drama-in-education to the domain of teaching and learning and probably language teaching. It further $x$-rays the mimesis concept of drama as a basis and model for language learning by explaining the three imitative models of language learning among humans as they relates to communicative activities: to prove the relevance of drama as a potent tool for fostering effective communication skills in English as Second Language Learners.

Keywords: Communication, Drama, Effective, TESL, Skills.
\end{abstract}




\section{INTRODUCTION}

Language in any human society is an important human heritage. The importance of language in human life cannot be over-emphasized. It is indeed central not only to our social interactions and relations, but also distinguishing us among other living things and enabling individuals to ascertain their status in the society. Longe and Ofuani (1996:13) defined language as "the system of communication in speech and writing that is used by people of a particular country or area". The above definition implies that language is a basic tool for communication. It is this function of communication and language as heritage that differentiates human beings from other species.

With the use of language for instance, human species have been able to make inventions, communicate ideas and spread such inventions and ideas from generation to generation. Today as a result of globalization, there have been increasing needs to interact at both official and unofficial levels. In particular, nationals of different countries have to move from one geographical region to another, needing a language of communication.

In Nigeria for instance, there are over 350 ethnic groups and over 400 languages. Agheyisi (2010:53) observes that "within Nigeria alone, it is estimated that nearly 400 languages are spoken; in Ghana, 42" While Dolphyne (1995:17) noted that "Sierra Leone has 16 languages". In the context of such multi-lingualism, it is expedient for government to stick to a neutral language such as English as official language. English has the additional advantage of long association, being the language of the colonial rulers. It is also a world language with various advantages to individuals who speak it nationally and internationally. Kachru (1986:63) thus observes that "competence in English and the use of this language signifies a transmutation; and added potential for material and social gain and advantages". One sees this attitude in what the symbol stands for; English is considered a symbol of modernization, an extra area for success and mobility in culturally and lingualistically complex and pluralistic societies.

It is therefore the quest for a lingua franca, common language for communication that some languages such as: English, French, Spanish, German, Arabic languages have become what can be described Second Language in many countries of the world. In other words, these languages have become the languages of communication, interaction and relationship.

Arising from the above explication; the role of English language in the educational process becomes inevitable. Gbenedio (1996:2) rightly observed that "English Language in Nigeria is the official language, the language of government, education, administration, national and international transactions and as well the language of the law courts, the mass media and commerce". Thus English enjoys a wider geographical spread than any of the indigenous languages within Nigeria. Whatever the language of discussion, a serious business transaction is sealed up in writing, in English language. The same goes for political campaigns which can be carried out in the language of the immediate environment and as well in English language that is widely accepted. Also manifesto and other documents are produced in English language. 
To this end, English language becomes important that it is introduced as a subject to be taught from the primary schools and used as a medium and subject of instruction from the third year through secondary school and tertiary education. In private schools for instance, especially in cosmopolitan areas; children are taught in English from kindergarten. To gain admission into any University faculty, a credit at $\mathrm{O}$ ' levels in English language is a prerequisite. It is only in very rare cases that a pass is considered at polytechnics, Monotechnics and colleges of education level. Thus in recent years, Oral English have also become an integral part of the secondary school syllabus and examination in English language. This is to enhance the mastery of Standard English as currently used by educated African writers and speakers of English among the Commonwealth Nations.

Suffice to mention at this juncture that the whole essence of English as a second language learning (ESL) in our schools, centred on communication, which is the basis for progress and development in every human society; also, the basis for associating, co-operating or joining an organization. The organization which is "English language studies" and "English language for communication" possesses a structure which we can describe as a set of rules grammar. Therefore, communication means "sharing of elements of behavior or modes of life by the existence of rules." In as much as people are in communication, they are said to be of one mind, or to understand one another. Hence, the essence of communication is to foster oneness, unity or an understanding. For this to happen, the rules must be subscribed to and understood by members of the organization. In other words, we must agree on, or come to an absolute understanding about the rules that govern whatever we are sharing; this therefore engenders the study of English as second language learning. Thus English language is handed down by the colonial masters, still remains the official language of communication, interaction and relationship in Nigeria. It is also the only one that is recognized as a subject to be taught, and to be used in teaching other subjects in Nigeria education system.

In spite of the fact that, English language has been accepted as the official language since colonial period: and its inclusion as a subject being taught, and as well as language of instruction at almost all levels of education system in Nigeria; many Nigerians literate and illiterate alike do not communicate fluently in the language. This is as a result of the fact that English language is not the first language of Nigerians. Labo-Popoola (2010: 32) observes that in Nigeria, "English language exists in relation to some major national languages such as Hausa, Igbo, Yoruba and many others, which total about 400 languages".

Many other researchers as well as "(WAEC) West African Examination Council, an African regional examination body have observed that the performance of students in English language has been very poor" (Agheyisi 2010:52). A similar trend of decline in English language proficiency among students of tertiary institutions in Nigeria has also been noted by researchers. Equally, it has been observed that there is deficiency in communication in English Language (Longe and Ofuani, 1996:4). All these shortcomings imply that although English language is taught in pre-primary, primary, secondary and tertiary institutions in Nigeria; students have not really shown competence in its use. The way students use English 
language in schools and colleges shows that their awareness and competence in the language leaves much to be desired.

It is imperative to note therefore that proficiency or otherwise of students in English language usually affect their performance in English language usually affect their performance in other subjects in the curriculum. Thus it is believed that incompetence in English language is responsible for education failure, especially in the second language situation, in which Nigeria finds herself. This is because literature have shown that a positive correlation exist between students' abilities in other subjects. It has been discovered that students who did well in English language performed better in other subjects. This invariably means that if a student is good at English language, he or she should be good in all other subjects. This is only logical as all other subjects are taught and examined in English language.

Consequent upon the above position, scholars and critics in the field of education have been of the opinion that students performance in English as second language learning depends largely on the teaching methodology adopted by the teacher or tutor. Thus, the teaching methodology determines the students' assimilation and retention capabilities. This is owing to the fact that the teaching methodology adopted may promote or hinder learning. It is therefore against this backdrop that this paper explores the potency, viability of drama as a useful tool for teaching English language as second language in school; kindergarten through secondary schools.

\section{THEORIES OF LANGUAGE ACQUISITION}

Generally, to explore the subject of teaching English through drama or creative dramatics, we must examine the evolution of the language acquisition domain (theories of language acquisition) and the concept of drama-in-education and how it has welded with the domain of teaching and learning. Basically, there are three major theoretical perspectives that guide the teaching and learning of language and learning in general today. Behaviourism, Mentalism and Cognitivism.

\subsection{Behaviorism or social learning view of language}

This first coherent theory of learning is based mainly on the work of Pavlov in the Soviet Union and of B.F. Skinner in the United States. This simple but powerful theory surmises that learning is a mechanical process of habit formation and proceeds by means of the frequent reinforcement of a stimulus-response sequence. According to this school of thought, every utterance speech is produced as a result of the presence of some kind of stimulus. Such stimulus could be internal or external, physical or verbal. For instance, language response to hunger, which is an internal state, could be the utterance "I am hungry." For a child to learn to make such a response, his attempt at producing the piece of language will have to be reinforced, and if reinforced, would likely lead to further utterances or at least the mastery of the initial utterances through repeated use.

This implies that the child cannot learn from situations that do not demand a response from him. In essence, one cannot learn a language simply by having language rules-grammar described or explained, or by only hearing others speak. 
Rather, he must practice that which he has heard and always react based on his experience - stimuli.

The effect of this behaviorist theory on language teaching implies that the learning of rules governing a language or the description of the principles underlying a language does not enhance the learning of the language; which the traditional English language teacher sets out to achieve in language teaching.

The behaviorist theory thus opines that formal explanations and rules should not be used for language teaching unless the spoken aspect of the language has been mastered. Constant practice in the use of the language being learnt is therefore the most important exercise. The teacher thus serves only as a guide providing the stimulus which would elicit the desired responses from the learners. The simplicity and directness of this theory hinges on the "stimulus-response concept" and the fact that second language learning should reflect and imitate the perceived process of mother tongue learning. In other words, learning through "direct experience" which drama-in-education tends to achieve is an alternative recipe in this situation.

\subsection{Mentalism}

This theory is advocated by Noam Chomsky in reaction against behaviorism as advocated by the Pavlov and B.F. Skinner linguistic school of thought. This theory upholds that "everybody learns a language, not because they possess an inborn capacity known as language acquisition device (LAD) which permits them to acquire a language as a normal maturational process" (Robert, 1996:249). Mentalists are of the view that a child after birth is exposed to language which usually triggers off the LAD.

According to Chomsky the LAD in each child has the capacity to formulate hypothesis about the structure of the language to which the child was exposed. It is an unconscious process as it takes place. Hypothesis so formulated are tested by the child in the course of further exposure to the language. If the child finds the language unacceptable when measured with what he hears the adults say, he modifies it and tests it again until his hypothesis is accepted. As a child gets older, the hypothesis gets more complex because his speech is beginning to approximate that of the adult speaker. This process is a construction of the internal structure of the grammar of the language being learnt.

Chomsky thus dismissed the generalization idea as unworkable, because it simply could not explain how from a finite range of experience, the human mind was able to cope with an infinite range of possible situations. His conclusion was that thinking must be rule-governed: a finite, and fairly small, set of rules enables the mind to deal with the potentially infinite range of experiences it may encounter. For this theory, language learning is not socially acquired. Also, the notions of reinforcement and repetition are not acceptable as necessary for language since learning will take place within the individual whether rewarded, experienced or not. In effect, the language learning process is not influenced by external factors; rather it involves an internal mastery of the rules of the language.

To this end therefore, drama techniques as a tool for teaching English language may have just little or no relevant since neither "direct experience" nor 
"stimulus-response concept" is necessary for language learning. Though through creative dramatics activities, the child is exposed to the language: therefore giving the child opportunities to test the hypothesis already formulated, to be accepted by his peers.

\subsection{Cognitive Theory}

This theory, "as offered by Slobin (1979) recognizes the importance of both innate mechanisms and learning" (cited in Robert, 1996: 249). This theory states that children possess certain information-processing abilities or strategies that they use in acquiring language. These are termed operating principle and seem to be present, or to develop, very early in life.

The cognitive view takes the learner to be an active information processor. To the cognitive theorists, learning and using a rule require learners to think, that is to apply their mental powers in order to distil a workable generative rule from the mass of data presented, and then to analyze the situations where the application of the rule would be useful or appropriate.

Learning, then, is a process in which the learner actively tries to make sense of data, and learning can be said to have taken place when the learner has managed to impose some sort of meaningful interpretation of pattern on the data. This may sound complex, but in simple terms, what it means is that we learn by thinking about and trying to make sense of what we see, feel and hear. Against this background, drama or drama technique is relevant to language learning because it poses problem solving tasks and critical thinking on individual learners. It offers language learners stimulus-response concept, direct experience which drama-in-education is set out to offer in individual learning process.

\section{CONCEPTUALIZING DRAMA-IN-EDUCATION}

Drama-in-education (D.I.E) is the use of drama as a means of teaching across the curriculum. It is used to expand learners' awareness, to enable them to look at reality through fantasy and to look below the surface of actions for meanings. According to McCaslin(1990:10) "the objective of drama-in-education is understanding rather than playmaking, although a play may be made in the process". Attitudes rather than characters are the chief concern as the focus is on process rather than product.

Fundamentally, drama-in-education has been appraised by scholars at different levels to be a potent tool in teaching. In that it provides learners with direct experience for effective learning, which our system needed. Through drama, we allow our students to explore the foundations of the surface reality. When we give students the background to a situation, or allow them to guess at it, we deepen their perceptions of the situation. When we ask the students; how do you think he/she, a particular character feels in a moment? How would you feel, if you were to be in his/her shoes? What will a particular character could be thinking at a given time? We unlock learner's own feelings of empathy with the person or situation being studied. 
When we ask students to improvise a continuation of a story, to supply introduction, or to offer alternative conclusions, we are stimulating their imaginations and their intellects. Then, when we finally ask students to "get up and do it," which is the main objectives of drama-in education; we are rewarding the student's efforts with our interest and attention, and their enjoyment of the doing the direct experience which drama offers.

The students often time benefit psychologically from their involvement in drama projects or activities especially when it comes to English language as second language learning and for effective communication. Rehearsing and performing a play in a target language improves the students' sense of confidence and self-esteem as learners, and this in its turn increase their motivation with respect to acquiring the target language. Thus Richard Via, one of the pioneers of drama-in-language teaching writes about this psychological spin-off that:

We get involved with putting on a play rather than with the task of learning English, and so we do what everyone who teaches English really hope to do - that is, to have the students learn by doing. We have fun, and the students will get great joy out of performing, and the audience, even the mothers and fathers who don't speak English will be happy and delighted to see the performance. You will have given the students a taste of success, which is so important... Success is important for everyone. So through drama, English becomes a living experience of communication. (Cited in Wessel, 1989:17)

\section{LANGUAGE LEARNING THROUGH DRAMA}

To further strengthen our argument on the potency of drama as a viable tool for teaching English Language, we shall establish the correlation between Language acquisition process and drama through imitation, with emphasis on imitative models as espouse by John Seely(1976). Literatures have shown that language could be acquired best through imitation. It is even much more possible when we use imaginary situations in order to extend our pupils experience of language. This becomes possible because of the residual propensity of human beings to imitate. Generally, imitative play occurs at all stages of human development, from early childhood to old age, but obviously, its uses for the individual and its general functions in human development vary considerably from stage to stage.

\subsection{The Exploratory Model}

The commonest model of imitative behaviour according to John Seely (1976), which is used to justify educational drama, is that of the exploratory dramatic play of childhood. An example would make this clear. Let us imagine a group of three children of Age Nine or Ten. One is hiding behind a low wall holding a stick as if it were a gun. Two others approach warily, not quite sure where he is. When they are almost up to him, he leaps out at them and subjects them to a withering burst of machine gun fire. One of them dies spectacularly and lays still, groaning slightly, but the other runs away, ducking and weaving as he runs.

"You are dead!" shouts the attacker 
"No, you missed," replies the fleeing child, and he stops to aim a single pistol shot at the attacker, who now takes up the chase. The dead man lies still.

Obviously, the movement and speech of the children are characterized by a number of qualities that have been observed by many writers on creative dramatics. The children are absolutely absorbed in what they are doing and their "acting" shows the sincerity of their capabilities: their movements are often graceful and agile; they are unaware of any audience their playing may accidentally have. At the moment of playing, their imaginative experience is to them real, if not real than real life.

It is apparently this type of imitative play that most theorists of educational drama have taken as the starting point of drama in school. Its function in human development is clearly important and relevant in language development among youngsters. It helps to develop physical and verbal skills; children can master experiences and emotions that would otherwise cause serious problems in true life situations (for example, the fear of death in the play just described); the child can make any experience "part of himself" by physically "doing-it drama"; and, through playing the roles of adult-life, children prepare for what is to happen to them later. Pemberton-Billing and Clegg (1965:39) argue that the school can use this process and develop it further than it might naturally go:

Through this play, the child learns to grow up. He comes to grips gradually with the real world...... The drama teacher's job is to discipline and direct the child's play into channels where he needs to make worthwhile discussions and discoveries.

There is no doubt that this "exploratory" model of imitative behavior is very useful for school drama - creative dramatics. If we can attain the right working conditions, in which the qualities of absorption, sincerity and unawareness of audience can be achieved, then we can use this type of imitative play as a means of exploring new experiences, and of coming to terms with feelings and thought that may otherwise be disturbing. We can also compensate for the narrowness and restrictions of the real worlds that many of our children live in, by providing a wealth of imaginative experience that will broaden their horizons. Linguistically, this is important: the resources of language are available to all, (see Language Acquisition Device: Mentalism Theory of language acquisition) as explained earlier, but the ways in which they are actually put to use will be determined by the culture in which a child is brought up. The drama teacher becomes relevant at this point.

\subsection{The Illustrative Model}

The second model as propounded by John Seely is the illustrative model that opines that other children, who are ten years and above seem to be more illustrative in their conversation. Thus the manner in which adolescents use imitations in their conversations suggest a different picture and perhaps engender an alternative model for older children above age ten. Let's take another scenario that conforms to the illustrative model of imitative behavior. A group of 12-year olds are talking to a teacher about the attitudes of adults. They come to the conclusion that in general, 
adults are very strict. When asked by the teacher what they mean by "strict", the children attempt to demonstrate it through various examples thus:

Olu: Some old people, I and Sola met at the bus-stop on our way to school today, we pushed in front of them. You known because the bus was there and we were in a hurry to enter, we went into the bus, and they got in with us and pulled us back......(Olu at this point adopts a high pitch voice)

"mmmmmmmer.........mmmmmmemmmm........mmmmmmmer......" they were talking like that.

Gbenga: Like my mum. Every time - I can't do anything right in that house. I get a bite of bread and butter to eat. (Gbenga raises his voice in imitation of an adult shouting across a room) What do you want to get that for? Tea again after you just finished eating few minutes ago! Get that back into the fridge!

Here, the imitative behaviour of the adolescents are characterized by qualities that are very different from those to be seen in the imitative activities of the younger children described above in "exploratory model". Here the speakers are very aware of their audience and imitation is no longer an end in itself. Instead, their imitative behavior is used to help them communicate with others in a social interaction. They imitate other people's behavior in order to back up some analytical point they wish to make: this type of person behaves in this way, they say, and here is an example to prove it.

Adolescents are very interested in the ways in which people behave and in the reasons for different form of behavior. Argyle (1969: 48) explains the reasons thus:

Conversation is mainly about other adolescents, parents, inter-personal feelings and social interaction. Such topics are discussed because adolescents have problems to solve in this area - as well as working out an identity and establishing a changed relationship with adults, they have to acquire the social skills of dealing with the opposite sex, to come to terms with the difficulty of playing different roles on different occasions, and having relationships of different degree of intimacy with different people.

In such conversation, the imitation of linguistic and/or paralinguistic behavior is used as a form of illustration. It may stay at the level of simple verbal copying, or take the more elaborate form of a full-scale acted impersonation; it will serve to prove a point, to stimulate discussion about ways of behaving in social interactions, or to enlighten the speaker's audience in some other way. For classroom purposes, this type of imitation is clearly easier to use and indeed it may come naturally into classroom discussion, as the conversation between Olu and Gbenga did. It is only a short step from this to getting a class to improvise the whole situation and then discussing with them the kind of imitative behavior it involved.

Underlying our behaviour in social situations, there is a wide range of assumptions on which we base our conduct. These cover not only appropriateness of language, and of social role, but things like how we interpret the posture and facial expression of a person we are talking to. Thus, an important part of growing up is 
learning to relate our own private "interpretative criteria" to those of the other people in our culture. Suffice to mention that when an imaginary situation is set up in which the emphasis is upon some aspect of social behavior, opportunities are provided both in the improvisation itself and in the following discussion for the participants to make explicit the assumptions that under-lie their behavior in such situations and that normally remain implicit.

\subsection{The Expressive Model}

The expressive model as propound by John Seely is the third model of imitative behaviour that is relevant to classroom drama. Though this is similar to the illustrative model but differs from it in several important aspects. It is best exemplified by the German playwright and poet Bertolt Brecht:

......an accident such as can be seen at any street corner; an eyewitness demonstrating to a collection of people how a traffic accident took place. The bystanders may not have observed what happened, or they may simply not agree with him, may "see things in a different way"; the point is that the demonstrator acts the behavior of a driver or victim or both in such a way that the bystanders are able to form an opinion about the accident..... The demonstration should have a socially practical significance. Whether our street demonstrator is out to show that on attitude on the part of the driver or pedestrian makes an accident inevitable where another would not, or whether he is demonstrating with a view to fixing the responsibility, his demonstration has a practical purpose, intervenes socially. (Cited in Bentley, 1968:22)

The emphasis is once again upon communication, but the circumstances and the setting alter the form of communication. It is far more public, for the speaker may well not know his audience, and the subject matter is broader and more complex. Rather than analyzing aspects of behavior in interpersonal relationships, the speaker is concerned to communicate both factual information about an event and comment on its general social significance. This is certainly close to the expressive form of adult theatre, but, as Brecht makes clear, it is a form of theatre in which what is communicated is important both to actors and audience.

This type of imitative behaviour is rather less common than the other two. Relatively, few people have the desire or the confidence to set up the kind of "oneman performance" described by Brecht. But it is surprising that children of Age fourteen and above can achieve this feat after consistent practice in classroom drama, because of the powerful influence that drama possessed.

Although three models of imitative behaviour have now been outlined, for classroom purposes, the first two - the exploratory and the illustrative; really need to be considered together. Growth into adolescence sees a natural move away from the absorbed, sincere type of imitative play that characterizes childhood towards a more conscious, even "calculating" use of it for illustrative purposes in social interactions. Thus, the easiest and most obvious way to begin using imitative behaviour in the classroom with adolescents with a view of language learning is certainly to set up an 
imaginary situation in which the students are mainly required to make some kind of comment on human social behavior. Initially, such comments may seem very superficial to the teacher, but he/she must make allowance for the novelty of the activity (in school classroom at least) and not in any case attempt to impose his own adult judgment in the early stages of the activities.

\section{DRAMA AND COMMUNICATIVE ACTIVITIES IN LANGUAGE LEARNING}

Communicative activities, as used in this context refer to the techniques which are employed in the communicative method in language teaching. Examples of such activities are games, exercises, practices and projects which make use of the target language. The activities involve 'doing' things with language e.g. making choices, evaluating and bridging the information gap. The language-using activity for communication is not restricted to conversation and may involve listening, speaking, reading, writing or an integration of two or more skills.

Communicative activities have the following characteristics:

I. They are purposeful. They are beyond strictly practicing particular structures.

II. They are interactive. The activities are often conducted with others and often involve some form of discussion.

III. Authentic materials are used. The situations in which the learners have to use language should be as realistic as possible. The language models given should be authentic.

IV. They are based on the information gap principle.

Raj (1984) has provided some guiding principles behind the use of communicative activities as language teaching and learning techniques. They are as follows:

1. Know what you are doing: This principle makes sure that each part of the lesson focuses on some operation which the student would want to perform in the target language. For example in teaching listening, the task could be to listen to the arrival and departure times of the aeroplane.

2. The whole is more than the sum of its parts: In communication, it is necessary to work in the context of the whole. Communication cannot easily be analyzed into its various components without its nature being destroyed in the process. For example you may teach the component of various forms of greeting but it is no guarantee that the student will be able to use it appropriately in a given situation.

3. The processes are as important as the forms: The processes of communication: information gap, choice, feedback, should be as far as possible replicated in trying to develop the ability of the student to communicate in the target language.

4. To learn it, do it: Only by practicing communicative activities would students learn to communicate. The role of the teacher thus changes. She no 
longer dominates the learning situation. She is there to provide all the help the student needs to play an active role in his own learning.

5. Mistakes are not always mistakes: There is the need for flexibility in deciding to treat different things as 'mistakes' at different stages of the learning process towards communicative competence.

The use of communicative activities is a technique to achieve one of the aims of the drama techniques / approach in language learning, which is to obtain communicative competence. The essence of this approach is to communicate with another person in the classroom and in the long term, the society. Thus, Drama used in the classroom can be considered a communicative activity since it fosters communication between learners and provides opportunities to use the target language in various 'make believe' situations.

According to Venugopal (1986), drama has been used for language teaching since the middle ages. The change in attitude towards the use of drama in language teaching came about due to a greater emphasis on meaningful communicative activities instead of mechanical drills.

Drama can be used in the teaching of English as a Second language for a variety of purposes.

I. Language is used in meaningful situations (Early and Tarlington, 1982 and Mordecai, 1985). Drama contextualizes the language in real or imagined situations in and out of the classroom. Language in the class that uses drama activities is explored, tried out and practiced in meaningful situations.

II. Drama activities can be used as a means of reinforcement of language learnt (Mordecai, 1985; Fernandez and CoIl, 1986). It helps to extend, retain and reinforce vocabulary and sentence structure through role-play and communication games.

III. Drama improves oral communication. As a form of communication methodology, drama provides the opportunity for the student to use language meaningfully and appropriately. Maley and Duff (1978) state that drama puts back some of the forgotten emotional content into language. Appropriacy and meaning are more important than form or structure of the language. Drama can help restore the totality of the situation by reversing the learning process, beginning with meaning and moving towards language form. This makes language learning more meaningful and attempts to prepare the student for real-life situations.

IV. Learning a second language can be enjoyable, stimulating and meaningful when combined with drama activities (Mordecai, 1985).

V. The problem of mixed ability is reduced when drama activities are used. Students who are more fluent can take the main roles which require more oral communication, while the weaker students compensate for their lack of linguistic ability by paralinguistic communication e.g. body language and general acting ability (miming).

VI. Holden Susan (1981), states that language learning must appeal to the creative intuitive aspect of personality as well as the conscious and rational 
part. Drama activities can be used to provide opportunities for the student to be involved actively. The activities involve the student's whole personality and not merely his mental process. Effective learning takes place as the student involves himself in the tasks and is motivated to use the target language.

The above are just some of the uses of drama in TESL - Teaching English as Second Language. The list is not exhaustive. Generally it can be said that the use of drama and drama activities in TESL do adhere to the aims of the learner achieving communicative competence. It is the hope of the advocators of the dramatic techniques, that the learner will become more imaginative, creative and sensitive as he becomes more self-confident in the process of learning English as a Second Language.

\section{CONCLUSION}

To this end, this study has provide basic explanation on the rationale and effect of using drama as a teaching English Language as a second language learning. Fundamentally, drama is apparently an active approach to learning where participants identify with roles and situations to be able to engage with, explore and understand the world they live in. this goes beyond language as social interaction, involves communication on multiple levels that cross-cultural and language boundaries. By being part of a drama ensemble and participation in a fictitious context, the class is experiencing a shared moment of intensity that involves emotions, facial expressions, gestures, movements and a heightened awareness of others that would not necessarily be experienced outside the drama environment. Students are thus freed from the constraints of precision of language that may be required in the conventional language classroom and are equipped with many other tools with which to communicate meaning.

Perhaps at the centre of all drama is communication. Like all the arts, drama allows students to communicate with and understand others in new ways. In fact, more than any art form, drama also provides training in the very practical aspects of communication so necessary in today's increasingly information-centred world. Students who have participated in dramatic activities are less likely to have difficulty speaking in public, will be more persuasive in their communications both written and oral, will be better able to put themselves together, put themselves into others' shoes and relate to them, and will have a more positive, confident self image. Participation in dramatic activity requires self-control and discipline that will serve the student well in all aspects of life. Students in drama usually learn to work together, to co-operate, and to find the best way for each member of a group to contribute, and to listen to and accept the view points and contributions of others. Drama indeed is a viable tool for preparing students to live and work in a world that is increasingly team-oriented and as well require effective and efficient communication to survive.

Thus, using drama as a tool for teaching English Language results in real communication; it give the teachers a wide option of learner-centred activities to choose for classroom teaching. Being extremely efficient in teaching English, 
drama is therefore an attractive alternative method or technique of teaching language because it gives a context for listening and meaningful language productionspeaking, forcing the students to use their language resources and, thus, enhancing learners' linguistic abilities. It provides situations for reading and writing, which are essential skills of communication. Drama as a unique tool is vital for language development as it simulates reality and develops self-expression. Drama techniques are equally successful in making students experience language in operation and provide motivation to use language embedded in a context and a situation, which could enhance effective communication.

\section{REFERENCE}

Agheyisi, R.N. (2010) "Minor Languages in Nigerian Context: Prospects and Problem" in Medwell Journals Vol. 5, Issue 1.

Argyle, Michael (1969) Social Interaction, London: Tavistock Publications.

Brecht, Bertolt (1939) Die Strassenszene, Grundmodel eines epischen Theatres (translated in Bentley, E. (1968) The Theory of the Modern Stage, London: Penguin.

Dolphyne, F. (1995) "A note on the English Language in Ghana" in Bamgbose et al (ed), The English Language in West Africa Perspective, Ibadan; Musore.

Dougili, John (1987) Drama Activities for Language Teaching. London: Macmillan.

Early, M. and Tarlington C. (1982) "Off stage: Informal drama in language learning". ELT Documents 1: 13.

Fernandez, L. and Coil, A. (1986) "Drama in the classroom", Practical Teaching 6:3, pp. 18-21.

Holden, Susan (1981) Drama in Language Teaching. England: Longman.

Gbenedio, U. B. (1996) Teaching and Learning English as second language, Ughelli; New Era Publication.

John, Seel (1976) In Context Language and drama in secondary school, Great Britain: Oxford University Press.

Kachru, B. B. (1986) The Alchemy of English: The Spread Functions and Models of Non-Native English, Oxford; Pergamon.

Longe, V. U. and Ofuani, A. Ogo. English Language and Communication. Benin City: Ilupeju Press.

Press Ltd 1996.

Labo-Popoola S. O. (2010) "The place of literature in The Teaching English as a second language", Medwell Journal, Volume 5, Issue 1.

Maley, A. and Duff, A. (1978) Drama Techniques in Language Learning. Cambridge: Cambridge University Press.

McCaslin, N. (1990) Creative Drama in the Classroom. 5th ed. Studio City: Players Press Inc.

Mordecai, Joyce (1985) "Drama and second language learning", Spoken English, 18:2, pp.12-15.

Pemberton-Billing, R. N. and Clegg, J. D. (1965) Teaching Drama, London: University of London Press. 
Raj, Devinder (1984) "Communicative Methodology" Journal Pendidikan dan Pembelajaran, 1:1 pp. 1- 5.

Robert, A. Baron (1996) Essentials of Psychology, Boston: Allyn \& Bacon.

Venugopal, Shanta (1986) "The use of drama in ELT: A perspective", The English Teacher, Journal 15:1, pp. 41-48.

Wessels, C. (1989) Drama, London: Oxford University Press. 